\title{
Sonlêncio: modulações da experiência de silêncio na cultura aural contemporânea
}

\author{
Soundlance: modulations of the experience of silence in contemporary \\ aural culture
}

\section{Vinicius Andrade Pereira}

Professor do departamento de Teoria da Comunicação da Faculdade e do Programa de Pós-Graduação em Comunicação da UERJ.

\section{RESUMO}

Ao considerar a quantidade de autores que exploram a problemática silêncio $X$ ruídos hoje, é possível afirmar que o mundo teria se tornado mais barulhento e cacofônico. Frente a essa possibilidade, surgem questões tais como: como compreender os significados e valores do silêncio na contemporaneidade? Seria o silêncio um objeto legítimo para o campo de Estudos do Som e da Comunicação? Pode a escuta do silêncio ser um aprendizado tal como a escuta de outros sons? É em busca de encaminhamentos para essas perguntas que o presente artigo se constrói, passando em revista boa parte da literatura, assim como práticas de consumo, tecnologias e materiais que tomam o silêncio como foco de suas ações. 0 estudo aqui apresentado propõe o termo "sonlêncio" como uma experiência silenciadora que se apresenta como uma importante modulação do silêncio na contemporaneidade que abre vias para se pensar, por fim, a cultura aural hodierna. PALAVRAS-CHAVE: Silêncio; Sonlêncio; Cultura Aural.

\section{ABSTRACT}

Considering the number of authors who explore the silence vs. noise problema today, it would be possible to state that the world has become noisier and more cacophonous. Faced with this possibility, questions such as these arise: how to understand the meanings and values of silence in contemporary times? Is silence a legitimate object for Sound Studies and Communication? Can listening to silence be as much of an apprenticeship as listening to other sounds? It is in search of 
referrals to these questions that the present article stands, reviewing much of the literature, as well as consumption practices, technologies and materials that take silence as the focus of their actions. This study proposes the term "soundlence" as a silencing experience that presents itself as an important modulation of silence in contemporaneity that opens up ways to think about aural culture today.

KEYWORDS: Silence; Soundlence; Aural Culture.

\section{RESUMEN}

Al considerar el número de autores que exploran la problemática silencio X ruído de hoy, es posible decir que el mundo se habría vuelto más ruidoso y cacofónico. Ante esta posibilidad, surgen preguntas como: ¿cómo entender los significados y valores del silencio en los tiempos contemporáneos? ¿Sería el silencio un objeto legítimo para el campo de los estudios de sonido y de la comunicación? ¿Escuchar el silencio puede ser una experiencia de aprendizaje como escuchar otros sonidos? Es en busca de direcciones possibles para estas preguntas que se construye este artículo, revisando una buena parte de la literatura, así como prácticas de consumo, tecnologías y materiales que toman el silencio como el foco de sus acciones. El estudio presentado aquí propone el término "sonlêncio" (un neologismo en portugués) como una experiencia silenciadora que se presenta como una importante modulación del silencio en los tiempos contemporáneos que abre formas de pensar, finalmente, en la cultura auditiva de hoy.

PALABRAS CLAVE: Silencio; Sonlêncio; Cultura Auditiva.

A sound accomplishes nothing; without it life would not last out the instant.

John Cage

\section{Introdução}

0 que vem à mente quando se pensa em uma metrópole? Provavelmente, imagens de grandes vias automobilísticas. Linhas de ônibus. Terminais de trens e metrôs. Prédios, muitos deles. Hordas apressadas cruzando faixas de pedestres nos semáforos, ocupando as calçadas, bares e restaurantes. Amplas e lúdicas vitrines. Grandes malls e shopping centers, com um entra e sai frenético de consumidores. Luzes publicitárias coloridas ao cair da noite, em grandes painéis de led e de vídeos de alta resolução. Hotéis iluminados ostentando luxo e mordomias para seus 
hóspedes. Movimento nas ruas 24 horas. Todas essas representações, que poderiam ser de cidades como São Paulo, Nova York, Londres, Paris ou Tóquio, são expressões visuais. Mas por que pouco ou quase nada vem à mente em termos de representações sonoras, quando se pensa nessas mesmas cidades?

Há diferentes encaminhamentos para a questão apresentada; um deles seria a ideia de que, desde o começo da história da difusão dos impressos - e antes da emergência das tecnologias reprodutoras de sons, como o gramofone, por exemplo -, é possível representar visualmente lugares, coisas, personagens e acontecimentos, mas não os seus sons e ruídos. Há uma cultura, quase universal, que gera e difunde representações visuais do mundo, mas muito pouco de suas representações sonoras.

Mesmo hoje, com as tecnologias de gravação de sons embutidas nas mídias digitais ao alcance de todos, encontram-se representações aurais do mundo, dos seus personagens e coisas, em uma proporção infinitamente menor do que aquelas oferecidas à visão. Um bom exemplo, a confirmar essa ideia no dia a dia, é o onisciente buscador Google, no qual, ao se digitar um verbete qualquer, além da semântica e das notícias a seu respeito, é oferecida a opção "imagens", através da qual se pode visualizar inúmeras representações iconográficas do tema pesquisado, mas nada é oferecido acerca das propriedades sonoras do mesmo.

Comparada à sonora, a cultura visual é muito mais ampla e diversamente representada, e isso pode ser confirmado ao se pensar que as formas e tecnologias de representar visualmente o mundo deixam produtos como pinturas, gravuras, desenhos e imagens em diversos suportes desde tempos imemoriais, em quase a totalidade das sociedades, enquanto que aquelas empregadas para representar auditivamente o mundo só puderam existir a partir do final do século XIX, e, assim mesmo, majoritariamente restritas a centros urbanos (Sterne, 2003). Às imagens, a permanência e a posteridade. Aos sons, o transitório e a efemeridade. Talvez isso possa explicar a força das imagens, em detrimentos dos sons, nos imaginários coletivos de diferentes sociedades.

Frente à hipótese da precariedade e desmaterialização dos registros de experiências sonoras - o que poderia ser tomado como adversidade metodológica

\section{Dossiê o Pensamento Ecológico - https://revistaecopos.eco.ufrj.br/}


para os estudiosos dos sons -, indaga-se, a partir do campo dos Estudos de Som (De Nora, 1992; Schafer, 2001; Thompson, 2002; Bull e Les Back, 2003; Sterne, 2003; Sá, 2010): poderia o silêncio gozar de algum privilégio como objeto de estudo? Pode-se argumentar que pouco ou nada se perderia com o fato de não haver registros audíveis do silêncio de diferentes épocas ou lugares. ${ }^{1}$ Nesse sentido, apenas o entorno cultural, social e político, ou seja, suas inscrições simbólicas, poderiam ser suficientes para seu estudo. Mas, mesmo que isso possa ser tomado como uma vantagem metodológica, por que estudar o silêncio hoje? Em que poderia tal objeto contribuir para a compreensão da singularidade da cultura aural contemporânea?

Há dois conjuntos de acontecimentos que vêm ao encontro das questões apresentadas e que ajudam na validação do estudo do silêncio hoje. Em primeiro lugar, o fato de, talvez desde Max Picard (1953) e John Cage (1961), nunca ter se escrito tanto e tão enfaticamente sobre o silêncio como na última década (Maitland, 2008; Foy, 2010; Prochnik, 2010; Voegelin, 2010; Castillo, 2011; Ochoa Gautier, 2015; Kagge, 2016; Corbin, 2018; Hanh, 2018; Brox, 2019).

Em segundo lugar, o fato de nunca antes terem sido oferecidos tantos aparelhos, tecnologias, produtos e práticas que buscam a indução de experiências silenciadoras. Encontramos no mercado uma infinidade de materiais antirruído dispositivos tecnológicos anunciados como capazes de produzir bolhas de silêncio (como o $\mathrm{Muzo}^{2}$ ), sons e ruídos variados (como o ruído branco, sons da natureza ou músicas do gênero ambient ${ }^{3}$, por exemplo), cujas frequências e/ou constâncias

\footnotetext{
${ }^{1}$ Ainda que, tecnicamente, seja possível gravar o silêncio - há, até mesmo um museu do silêncio na forma de website, onde se poderia ouvir diferentes tipos de silêncios, a partir de mediações tecnológicas (http://20decibel.blogspot.com/ ) -, o artigo adota a perspectiva de que tal prática não se dá como algo comum e disponível como material de consulta regular, referente a diferentes contextos e momentos históricos, para um estudioso da cultura aural.

2 Basicamente, a proposta do Muzo e de tecnologias afins é criar ondas sonoras cujas frequências sejam capazes de neutralizar ruídos e sons indesejados, gerando uma zona de conforto aural, semelhante a uma situação de silêncio ou próxima a isso. Uma rápida apresentação da tecnologia, que será retomada mais à frente neste texto, pode ser vista neste vídeo: https://www.youtube.com/watch?v=Y3kilRJ4BxA

3 Uma definição correta do gênero é encontrada na Wikipedia, onde se pode ler: "Música ambiente (ambient music) é um gênero musical substancialmente focado nas características timbrais dos sons, geralmente organizados ou executados com o intuito de se denotar ou estimular a criação de uma 'atmosfera', uma 'paisagem sonora' ou mesmo para apenas soar como um 'discreto complemento' a uma ambiência." Cf. em https://pt.wikipedia.org/wiki/M\%C3\%BAsica ambiente
}

Dossiê 0 Pensamento Ecológico - https://revistaecopos.eco.ufrj.br/

ISSN 2175-8689 - v. 23, n. 2, 2020

DOI: 10.29146/eco-pos.v23i2.27459 
sonoras anulariam outros sons e barulhos indesejados - além de práticas como a meditação, retiros de silêncio, etc.

Todo o cenário brevemente esboçado parece já legitimar a importância de se estudar o silêncio hoje, mas há ainda mais em jogo. 0 silêncio se presta a diferentes significados na cultura contemporânea. Também os valores em relação ao silêncio oscilam - ora positivo, ora negativo, ora ambos os valores se apresentando conjuntamente. Como aponta Ochoa Gautier: "A tensão entre a aparente impossibilidade acústica do silêncio e as experiências intensamente contrastantes que ele provoca está no cerne dos tipos de presença e afeto invocados pelo termo." (Ochoa Gautier, 2015). Pela variedade de sentidos e de valores que ganha, o silêncio, tal como o som e a música, se revela como um agente organizador de espaços, movimentos e corpos, propondo arquiteturas, inclusões e exclusões, rupturas e junções, encontros e separações, potência e impotência, liberdade e confinamento.

Com todos os pontos esboçados, afirma-se o silêncio como o objeto central do presente texto, recortado mais especificamente em torno de como ele é experimentado na contemporaneidade. Como objetivos do artigo, busca-se identificar e compreender melhor alguns fatores que participam da experiência da escuta do silêncio hodiernamente. Particularmente, interessa explorar o que parece ser uma relevante modulação desta experiência, para a qual se propõe o termo sonlêncio. Nesse sentido, serão objetivos do estudo, ainda, explorar alguns significados e valores que o silêncio ganha, bem como algumas das suas práticas culturais, mercados e modos de consumo. Por fim, serão identificados e pensados alguns pontos implicados no aprendizado da experiência de escuta na contemporaneidade.

\section{Sentidos do Silêncio}

O fato de tantos autores se dedicarem ao silêncio na última década pode ser indício de que o mundo atual se tornou excessiva e prejudicialmente ruidoso. Das leituras empreendidas pode-se retirar alguns sentidos para a ideia de silêncio que

\section{Dossiê o Pensamento Ecológico - https://revistaecopos.eco.ufrj.br/}

ISSN 2175-8689 - v. 23, n. 2, 2020

DOI: 10.29146/eco-pos.v23i2.27459 
demonstram, contudo, que não há unanimidade em torno do termo, apesar de todos o valorizarem e o defenderem enfaticamente. Mas, afinal, de que silêncio falam tais autores?

George M. Foy, em seu livro Zero Decibels: The Quest For Absolute Silence (2010), argumenta que o nível de ruídos em alguns locais de uma grande cidade como Nova York - como em plataformas e estações de metrô, por exemplo - teria chegado a níveis tais que a convivência com essa condição aural comprometeria a saúde física e mental. Foy sustenta seu argumento em uma série de estudos que demonstram de que forma o aumento do volume de ruídos, medidos em decibéis (dB) em grandes cidades ao redor do mundo, estaria diretamente associado a males diversos, tais como aumento da pressão arterial, riscos cardíacos, perda da audição, perda da concentração no trabalho, irritabilidade, insônia e até mesmo a morte. A tese central do livro é demonstrar a perda da capacidade humana de conviver com o silêncio e, mais ainda, a perda de valor do silêncio como uma experiência rica e necessária, clamando pela urgência em retomar o silêncio como experiência vital. (Foy, 2010)

Alain Corbin, em History of Silence (2018), afirma que o ruído se torna um traço da sociedade contemporânea e que a perda do silêncio dificulta um sentimento de calma e impede o conhecimento de si mesmo:

É difícil ficar em silêncio nos dias de hoje, o que nos impede de ouvir o discurso interior que acalma e apazigua. A sociedade exige que aceitemos o ruído para sermos parte do todo, em vez de ouvirmos a nós mesmos. (Corbin, 2018, p.02, minha tradução)

Em um outro trecho, ao abordar os possíveis responsáveis pelo desaparecimento do silêncio nos dias atuais, Corbin exime as dinâmicas urbanas veículos de transportes, bares, restaurantes, comércio etc - e deixa transparecer uma outra perspectiva para se entender o silêncio, que se aproxima da ideia de um silêncio interior:

0 principal culpado não é, no entanto, como se poderia pensar, uma intensificação do ruído geral da vida urbana (...) o que é novo é a

\section{Dossiê 0 Pensamento Ecológico - https://revistaecopos.eco.ufrj.br/}


hipermediatização e a conectividade permanente e, em consequência, o fluxo incessante de palavras que são impostas às pessoas e que as fazem temer o silêncio. (Corbin, 2018, pp. 02-03, minha tradução)

Retomando Foy, nota-se que ele se aproxima de Corbin quando aponta que também os excessos das comunicações digitais atuariam como corresponsáveis por essa condição aural contemporânea de perda do silêncio, insinuando também um sentido de silêncio interior para o termo:

Há outra forma de som hostil, cujo volume não é necessariamente alto, mas que se espalha como poeira doméstica. É o barulho da informação inútil. É a conversa de fundo constante de rádios, TVs, iPods, aparelhos de som, videogames, telefones celulares, podcasts, áudio. São as chamadas de marketing (...) (Foy, 2010, pp.132-133, minha tradução).

À luz da crítica dos autores citados, pode-se depreender que mensagens diversas - textuais, imagens, fotos, memes, animações etc. -, mesmo que silenciosas, serão tomadas como ruídos. Assim, tudo aquilo que circula através das mídias contemporâneas e que pode chamar e ser foco de atenção comprometeria a experiência de silêncio, funcionando como ruído. Ao que parece, à medida que o silêncio ganha sentidos outros, o mesmo se dá com o seu par antagônico, o ruído. Mesmo os pensamentos comprometeriam o silêncio e poderiam também ser significados como ruídos. Essa perspectiva é especialmente clara para praticantes de meditação do tipo mindfulness (atenção plena), e é nesse sentido que o monge budista Thich Nhat Hanh escreve:

Mesmo nos raros momentos em que não existe som, texto ou qualquer outra informação vinda de fora, nossas mentes vivem ocupadas por um fluxo constante de pensamentos. Quantos minutos ao dia - se é que isso acontece - você passa realmente em silêncio? (Hanh, 2018, posição 189 de 1700, ed. Kindle)

O que se pode notar nas reflexões dos três autores citados é que a temática som/ruído/silêncio salta de um plano aural para o visual e, mesmo, para o plano mental. Este deslizamento de planos sensoriais e cognitivos onde ocorreriam as 
experiências de silêncio, ou interrupção deste, confirma de modo ainda mais enfático a polissemia do termo silêncio na contemporaneidade.

Sara Maitland atesta algo semelhante no que concerne à perda do silêncio na cultura contemporânea, e confirma as possibilidades de diferentes entendimentos para o silêncio, ao afirmar que, "seja ele qual for", precisaria ainda ser mais bem compreendido. Assim, escreve: "Enquanto sociedade, estamos a perder algo de precioso na nossa cultura, que evita cada vez mais o silêncio e que, seja ele qual for, necessita, de algum modo, ser conservado, alimentado e desvendado." (Maitland, 2008, p. 38-39)

O norueguês Erling Kagge, de modo próximo e ecoando as palavras dos demais autores, afirma simples e peremptoriamente: "Vivemos na era do ruído. 0 silêncio está ameaçado" (Kagge, 2016, posição 252 de 1149, ed. Kindle). Contudo, ao discorrer sobre sua experiência de descoberta e valorização do silêncio, alega ter compreendido que a satisfação dessa experiência não se restringiria ao silêncio entendido apenas como a ausência de ruídos no mundo, mas também como silêncios outros, inclusive como silêncio interior, como uma "experiência pessoal", conforme explica:

O silêncio se parece mais com uma ideia. Um sentimento. Um conceito. 0 silêncio ao seu redor pode conter muitas coisas, mas para mim o silêncio mais interessante é aquele que trago dentro de mim. Um silêncio que de certa forma eu posso criar sozinho. Por isso não busco mais o silêncio absoluto ao meu redor. 0 silêncio que busco é uma experiência pessoal. (Kagge, 2016, posição 145 de 1149, ed. do Kindle.)

Kagge amplia ainda mais os sentidos do silêncio ao mencionar um "silêncio dentro de si" que se relacionaria com um "silêncio absoluto", passível de ser experimentado através de atividades que, paradoxalmente, em uma perspectiva acústica, seriam produtoras de sons e ruídos diversos, tal como descreve:

Acredito que todos podem encontrar o silêncio dentro de si. Ele está lá o tempo inteiro, mesmo quando existem vários sons ao redor de nós. Nas profundezas do mar, sob as oscilações e as ondas, tudo parece estar em silêncio. Postar-se debaixo do chuveiro e deixar a água escorrer pela cabeça, sentar-se em frente a uma fogueira crepitante, nadar em um lago 
no meio da floresta ou fazer uma caminhada por uma planície são experiências que podem ser percebidas como silêncio absoluto. (Kagge, 2016, posição 154 de 1149, ed. do Kindle.)

Kagge propõe, ainda, ideias como a de se "criar seu próprio silêncio", que poderia se dar mesmo em cenários ruidosos, como em uma grande cidade: "Você não pode esperar que o mundo faça silêncio. Nem em Nova York nem em outros lugares. Você precisa criar seu próprio silêncio." (Kagge, 2016, posição 380 de 1149 , ed. do Kindle)

Por fim, tornando ainda mais complexo o arranjo de feixes semântico do termo, pode-se acolher a proposta do artista John Cage, para quem o silêncio não existiria, uma vez que a mente e o corpo humano sempre produzirão sons e ruídos que impossibilitarão a experiência de uma escuta silenciosa absoluta. Tal perspectiva se revela ao artista quando ele tem a oportunidade de imergir em uma câmara anecoica, na Universidade de Harvard, como escreve:

Não existe um espaço vazio ou um tempo vazio. Há sempre algo para ver, algo para ouvir. De fato, por mais que tentemos fazer silêncio, não podemos. Para determinados fins de engenharia, é desejável ter uma situação tão silenciosa quanto possível. Tal sala é chamada de câmara anecoica, suas seis paredes cobertas de material especial, uma sala sem ecos. Entrei em uma dessas na Universidade de Harvard há vários anos e ouvi dois sons, um alto e um baixo. Quando os descrevi ao engenheiro encarregado ele me informou que o mais alto era o meu sistema nervoso em funcionamento, o baixo meu sangue em circulação. Até eu morrer haverá sons. E eles continuarão seguindo minha morte. Não é preciso temer quanto ao futuro da música. (Cage, 1961. p. 8, tradução minha)

A experiência em Harvard parece revelar a Cage algo extremamente significativo e ainda pouco discutido, e que ele carregará pelo resto da sua jornada como artista: que o menor conjunto de sons possíveis em um ambiente será sempre revelador de outros sons. Vem daí a sua famosa ideia contida na passagem citada acima, de que o silêncio absoluto é impossível. Tal aprendizado permitiu a Cage utilizar-se do silêncio como uma estratégia para possibilitar que o mundo fosse escutado, mais detalhada e amplamente, como ocorre na sua hoje famosa peça 4'33'. 
Sugere-se, assim, que a grande revelação que a experiência da imersão na câmera anecoica oferece a Cage não deve ser compreendida apenas na negatividade da impossibilidade do silêncio, mas na positividade da descoberta de um novo universo sonoro, da escuta do mundo. A revelação que se apresenta a Cage permite pensar, por extensão e de modo invertido, como o silêncio pode ser experimentado a partir do ruído. É exatamente disso que se trata a experiência do sonlêncio, apresentada em seguida.

\section{Sonlêncio}

Com a emergência e onipresença da cultura digital, a cultura aural contemporânea ganha todo um conjunto novo de sons e ruídos. Em estudo anterior, apresentaram-se alguns desses novos produtos sonoros, reunidos em torno do que se nomeou como "M.E.R.S.B.E - Mercado de Ruídos e Sons para o Bem Estar" (Pereira, 2018). Com o aprofundamento deste estudo, um novo objeto se revelou aos poucos, como uma espécie de "subproduto" ou, mais ainda, como uma espécie de experiência aural ou fim buscados por muitos consumidores daquele mercado: o silêncio.

O silêncio em questão, contudo, deve ser entendido como uma experiência de escuta única, que tem como objetivo a conquista de um efeito silenciador, mais do que a conquista do silêncio propriamente - entendido como ausência de sons e/ou ruídos. ${ }^{4}$ Tal efeito seria obtido, na maioria das vezes, recorrendo à escuta, quase sempre com o auxílio de fones de ouvido, de material sônico específico oferecido pelo M.E.R.S.B.E..

O objetivo dessa experiência de escuta silenciadora, que no presente estudo é nomeada como sonlêncio ${ }^{5}$, seria bloquear sons e/ou ruídos indesejados, sejam

\footnotetext{
${ }^{4}$ Como será demonstrado mais à frente neste artigo, não há um sentido inequívoco para o termo silêncio quando se considera diferentes autores que se debruçam sobre o tema. Por ora, será suficiente a definição que o propõe como ausência de sons ou ruídos, passível de medição em decibéis, e que se aproximará do que será apresentado como silêncio exterior.

${ }^{5}$ A proposição do neologismo sonlêncio, como se pode deduzir do próprio termo, implica e funde as ideias de som e de silêncio. Isso se justifica pelo fato de a experiência silenciadora à qual o sonlêncio se refere implicar a escuta de sons ou ruídos em favor de uma simulação de silêncio. Para a língua inglesa, em vez de se evitar a tradução do termo, propõe-se o neologismo soundlence.
}

\section{Dossiê 0 Pensamento Ecológico - https://revistaecopos.eco.ufrj.br/}


exteriores - como conversas alheias em um espaço público, ruídos inoportunos vindo de quartos ou apartamentos contíguos, ruídos de transeuntes ou carros da rua, ruídos de elevadores etc. -, sejam sons e ruídos interiores - como zumbido de ouvido (tinido) ou sons e vozes do pensamento, no caso da prática da meditação. Dentro do universo de um site agregador de vídeos, como o Youtube, pode-se encontrar uma infinidade de propostas de escutas que se enquadrariam como sonlêncio. ${ }^{6}$

Há algumas variações da prática do sonlêncio como, por exemplo, o uso de fones de ouvido que cancelam ruídos ambientes (noise-cancelling headphone), máquinas de reprodução de ruídos diversos ${ }^{7}$ e até mesmo usos "desviantes" de tecnologias domésticas, como um ventilador ou aspirador de pó para a produção de material sônico adequado à prática silenciadora em questão.

Se o sonlêncio pode ser entendido como uma prática silenciadora que modularia a escuta do silêncio na contemporaneidade, na medida em que busca um efeito silenciador equivalente à ausência de sons e ruídos, caberiam algumas questões: será que a cultura aural contemporânea seria tão mais cacofônica e barulhenta a ponto de mesmo o silêncio só poder existir através de práticas que incluam a escuta de ruídos? Isso poderia significar que o silêncio estaria, assim, sendo banido progressivamente da cultura aural contemporânea? Ou, ao contrário, a experiência silenciadora que o sonlêncio oferece seria uma resposta criativa e afirmativa que resgata o silêncio e o reintroduz, ainda que modulado, em um mundo saturado por altas cargas sônicas? Ou, ainda, será que não se trataria de incluir ou excluir o silêncio na contemporaneidade, mas sim de confirmar o que o músico John Cage (1961) afirmara, que o silêncio é uma experiência impossível, já que a experiência em si será sempre repleta de sons e ruídos?

Todas as questões levantadas forçam a pensar melhor os diferentes significados da ideia de silêncio na contemporaneidade, trazidos pelos autores

\footnotetext{
6 Veja pequena amostra em https://www.youtube.com/results?search query=white+noise+silence, encontrada ao pesquisar os termos tais como "white noise silence".

${ }^{7}$ Exemplos de máquinas que reproduzem ruídos coloridos e sons da natureza, usadas nas práticas de sonlêncio, podem ser ouvidas em: https://www.tuck.com/white-noise-machine-reviews/
} 
citados e pela ideia de sonlêncio. É o que se apresenta na subseção seguinte, onde se oferece chaves de significação que buscam reduzir a polissemia do termo.

\section{Quatro perspectivas para o entendimento do silêncio na contemporaneidade}

Com o objetivo de sintetizar os muitos sentidos apresentados por diferentes autores para a experiência de silêncio, incluindo a modulação desta experiência na forma do sonlêncio, quatro chaves de significação são propostas em seguida, a saber, silêncio exterior, silêncio interior, silêncio relativo e o próprio sonlêncio, apresentado acima. Aposta-se que estas chaves de significação contemplam a grande maioria, se não a totalidade, das experiências de silêncio na contemporaneidade.

Como silêncio exterior deve-se entender a ausência de sons e ruídos materiais. Essa seria uma definição mais difundida e aceita, na qual o sentido de silêncio seria sustentado por sua dimensão material. Assim, esse tipo de silêncio é passível de ser mensurado por um aparelho como o audiodosímetro ${ }^{8}$, no qual marcas próximas a zero decibel $(\mathrm{dB})^{9}$ constatariam, tecnicamente, a condição de silêncio. Este é o tipo de silêncio passível de ser controlado e de ser forjado, como em câmaras anecoicas, por exemplo.

O silêncio interior seria uma condição mental na qual fluxos de pensamentos, verbais, visuais ou sonoros, devem cessar, conquistando-se um estado de silêncio pessoal e particular, independente dos sons e ruídos do ambiente. Este modelo de silêncio estaria fortemente vinculado às práticas de meditação, particularmente a conhecida como "atenção plena", ou "mindfulness", onde se deve buscar cessar os pensamentos em favor de processos de percepção do aqui e agora.

O silêncio relativo deve ser entendido como uma experiência de silêncio decorrente de quando o foco da atenção se restringe a um determinado ponto -

\footnotetext{
${ }^{8}$ Aparelho que detecta em decibéis a presença e intensidade dos sons. Uma busca no Google permite encontrar inúmeras ofertas do aparelho, assim como sua definição mais detalhada. Ver, por exemplo, em: https://pt.wikipedia.org/wiki/Audiodos\%C3\%ADmetro

9 Decibel (dB) é a unidade de medida do som ou ruídos.
}

Dossiê o Pensamento Ecológico - https://revistaecopos.eco.ufrj.br/ 
que pode ser um som/ruído ou não - e, então, todo o resto do mundo emudece. Esse é um tipo de silêncio que, por exemplo, leitores experientes conseguem produzir, silenciando o seu entorno enquanto leem.

O sonlêncio, por fim, tal como foi definido acima, se apresenta como uma quarta chave de significação, na medida em que, como experiência silenciadora, pode se equivaler às demais experiências de silêncio. Tal equivalência é notada de modo mais claro quando cotejamos a temática dos significados do silêncio com o conceito de entropia, apropriado pela Teoria da Informação, que pode ser rentável, ainda, para uma exploração do tema inspirada nas materialidades (Boivin, 2009).

\section{Silêncio e Entropia}

Dialogando com a Teoria da Informação, recorrer ao conceito de entropia pode se revelar oportuno para se pensar como as quatro perspectivas de silêncio apresentadas - silêncio exterior, silêncio interior, silêncio relativo e sonlêncio podem se equivaler e, assim, diminuir a polissemia contemporânea do termo silêncio.

Entropia é um conceito derivado diretamente da segunda lei da termodinâmica, que afirma que todos os sistemas fechados - sem trocas com o seu meio - tendem à homogeneização com o meio em que estão inseridos e, assim, à deterioração como sistemas autônomos e singulares. Um exemplo que torna visualizável esta ideia seria um cubo de gelo abandonado - tomado como um sistema fechado, isto é, sem trocas com o meio ambiente - sobre uma dada superfície cuja temperatura esteja acima de zero grau Celsius. A tendência, com o passar do tempo, será o gelo se desfazer, perder suas características como um sistema singular e distinto do meio ambiente, até se liquefazer e se evaporar. Quando isso acontecer, o grau de entropia será máximo e as moléculas do que outrora fora o cubo de gelo tenderão a estar distribuídas, no meio ambiente, de modo equidistante e indiferenciado.

Uma situação oposta seria a de um animal em uma floresta na qual viva, em que o animal seja tomado como o sistema e a floresta, o meio. 0 animal, ao

\section{Dossiê 0 Pensamento Ecológico - https://revistaecopos.eco.ufrj.br/}


contrário do cubo de gelo, é um sistema aberto que efetua trocas com o meio. 0 animal se alimenta do meio e excreta substâncias diversas nesse mesmo meio. Essas trocas reduzem momentaneamente a entropia no animal, de modo a mantêlo preservado como sistema, até o dia da sua morte, quando cessarão as trocas com o meio e, tal como o cubo de gelo, com a passagem de tempo devida ele se desintegrará como sistema, em um grau máximo de entropia.

A entropia é um conceito que se aproxima do campo da Comunicação, ao ser explorada, a partir da Cibernética, com Wiener, pela Teoria Matemática da Comunicação, com Shannon e Weaver, e pela Teoria da Informação. Nesse contexto, a entropia deve ser pensada a partir de sua relação inversa à informação: quanto mais informação, menos entropia e vice-versa. Esta relação é mais bem compreendida quando se pensa que sistemas são tomados como blocos de informações estruturadas, sendo informação aquilo que pode ser notado ou observado como diferença. Por exemplo, em um conjunto de 51 letras no qual 50 são letras A e apenas uma é a letra $\mathrm{B}$, esta será o elemento percebido como diferente e, portanto, como informação.

A proposta que aqui se constrói é pensar o silêncio como uma das inúmeras expressões da entropia. Neste caso, o silêncio deve ser pensado como um sistema sônico hipotético, no qual os elementos que o constituem estariam dispersos de tal modo pelo meio que seriam imperceptíveis, inaudíveis. 0 silêncio seria, assim, não necessariamente a ausência absoluta de sons ou ruídos, mas a não percepção dos mesmos. Em um ambiente silencioso, a ausência de informação (sonora) seria total e, assim, a entropia seria máxima. Qualquer som ou ruído que comparecesse e que pudesse ser escutado em tal contexto funcionaria como informação, sendo percebido como a diferença emergente entre o estado de silêncio (entropia máxima) e o som que agora é percebido (entropia reduzida).

Em uma perspectiva empírica, pode-se dizer que um ambiente de entropia máxima é privado de informações, uma vez que todos os elementos que ali possam estar dispostos não podem ser percebidos diferenciadamente. Nesse sentido, pouco importa se o ambiente está repleto ou carente de elementos quaisquer. Os efeitos sensoriais e cognitivos serão praticamente os mesmos nessa situação, a

\section{Dossiê o Pensamento Ecológico - https://revistaecopos.eco.ufrj.br/}

ISSN 2175-8689 - v. 23, n. 2, 2020

DOI: 10.29146/eco-pos.v23i2.27459 
saber, como se não houvesse informação relevante e, portanto, nada a ser percebido, ou conhecido.

A ideia acima pode ser aplicada perfeitamente ao silêncio e à ideia de prática silenciadora do sonlêncio, uma vez que se considere que tanto no silêncio como ausência de sons -, quanto no sonlêncio - quando não se percebem outros sons, além da massa ruidosa que conduz a experiência em si -, o efeito é o de que nada, nenhum som ou ruído, comparece como diferença, como informação, e, dessa forma, nada é percebido, ou escutado. Por isso se pode afirmar que, em termos entrópicos, silêncio exterior, interior, relativo e sonlêncio se equivalem.

Se os significados do silêncio podem encontrar equivalência recorrendo à ideia de entropia e à Teoria da Informação, o que dizer quanto aos valores do silêncio na cultura contemporânea? É disso que trata a subseção seguinte.

\section{Valores do Silêncio}

Considerando que o silêncio ganha diferentes significados, como pensar os seus valores na contemporaneidade? Tal questão implica cotejar dois vieses opostos. ${ }^{10}$ Há o viés negativo, para o qual a ausência de sons ou de fala pode ser resultado de restrições, deficiências, proibições e/ou códigos de conduta impostos. Esse viés articula o silêncio, em última instância, ao isolamento e à nãocomunicação. E há um viés positivo, para o qual o silêncio é potência, é um meio para a emergência de sons, de mensagens e de vozes. Nessa perspectiva, o silêncio é fonte de sabedoria e meio para a comunicação - consigo mesmo e/ou com Deus.

Ana Maria Ochoa Gautier ressalta esses valores extremos que o silêncio pode ganhar:

Por um lado, o silêncio invoca um tipo de plenitude mais comumente associado a técnicas contemplativas de quietude como meio de provocar uma transformação do eu (Merton, 1996; Corbin, 1997). Por outro lado, o silêncio está associado a uma "ressonância sinistra" (Toop, 2010) que invoca uma assombração; os perigos e o medo do desconhecido; as

10 Tais vieses seriam colhidos em um recorte histórico que tem como referência a obra de Alain Corbin $A$ History of Silence - From the Renaissance to Present Day (2018).

\section{Dossiê 0 Pensamento Ecológico - https://revistaecopos.eco.ufrj.br/}


inseguranças produzidas pelo inacessível e pela profunda irreversibilidade da morte. (Ochoa Gautier, 2015, pp.183-184, tradução minha)

Em uma perspectiva negativa, o silêncio se apresenta como algo que é subtraído de uma experiência maior na vida, na maioria das vezes à revelia de quem é silenciado. Tal subtração implica tanto uma dimensão sensorial, quanto uma dimensão comunicacional. Há muitas formas de imposição do silêncio, dentro desta perspectiva.

O silêncio pode se impor a partir de restrições materiais (geográfica, arquitetônica/acústica) ou tecnológicas (corte de linhas telefônicas, de cabeamentos de internet, de bloqueio de aparelhos de telecomunicação etc.). 0 silêncio pode ser o resultado de uma condição humana especial - circunstancial ou não -, imposta por motivos os mais diversos, tais como, por exemplo, o desconhecimento de uma língua, uma deficiência física, mental e/ou cognitiva, um traço de personalidade como a timidez extrema, um problema de audição etc. 0 silêncio pode, ainda, ser resultado de uma proibição expressa ou um código de conduta, como no caso de sistemas e poderes opressores, sejam institucionais (religiosos, militares, educacionais etc.), políticos (ditaduras), criminosos (como a omertá, código de silêncio da máfia italiana) etc.

Em todos os exemplos apresentados, observa-se uma identificação do silêncio com a não-comunicação e, em boa parte deles, com o isolamento, com a solidão e, em última instância, com a morte. Pode-se afirmar que a perspectiva negativa de silêncio, de maneira geral, toma o silêncio como um fardo a ser carregado, normalmente sob imposição do acaso ou de terceiros.

Em uma perspectiva radicalmente oposta, ganhando um viés positivo e muitas vezes voluntário, o silêncio é tomado como uma presença e não como ausência, potência e não deficiência, e valorizado como experiência capaz de evocar sons, ruídos e/ou vozes. Isso vale tanto para investigações materiais em torno do silêncio, exploradas em experimentos acústicos e artísticos, seja em experiências religiosas ou místicas, nas quais o silêncio é tomado como um meio de contato com a interioridade e/ou com Deus (Picard, 1953). Diante do silêncio, há o 
florescer de sons interiores, sejam materiais - os sistemas circulatório e nervoso, no caso do silêncio experimentado por Cage na câmara anecoica -, sejam sons espirituais - vozes do interior e/ou de Deus, para os místicos e religiosos (Maitland, 2008). O silêncio, revela-se, assim, como uma comunicação, como uma presença, como um meio aural.

Ao considerar as formas de consumo do silêncio na contemporaneidade, pode-se afirmar que o valor do silêncio hoje encontra sua melhor representação no viés positivo. E isso se expressa de modo mais notável no seu extremo, quando o silêncio se torna, para além de um valor agregado aos produtos comercializados, ele mesmo um dos produtos avidamente consumidos. A subseção que se segue trata dessa questão, especificamente.

\section{Consumo do silêncio e de práticas silenciadoras na contemporaneidade}

Pensar o consumo do silêncio e de práticas silenciadoras na contemporaneidade implica pensar, também, as condições e variáveis que estimulariam tais práticas. Como visto, o silêncio ora é valorizado e afirmado positivamente, ora é tomado como um fardo e desvalorizado, como um órgão ou membro amputado, que limita e implica uma condição de não comunicação.

Se o silêncio for considerado como silêncio exterior, pode-se dizer que há uma gama de estudos que sugerem que, de fato, as cidades contemporâneas se tornam mais ruidosas, apesar de uma maior consciência e preocupação com a poluição sonora hoje, em comparação ao passado recente (Foy, 2010; Castillo, 2011; Prochnik, 2018). O simples fato de existirem hoje muito mais estudos, aparelhos, metodologias e mesmo leis que buscam conhecer, monitorar e controlar o barulho em grandes cidades evidencia uma percepção mais acurada sobre o tema, relacionado diretamente ao aumento contínuo e progressivo da densidade demográfica urbana (Foy, 2010).

Tomado em outra perspectiva, como silêncio interior, pode-se dizer que há uma unanimidade em relação à maneira como os usos de tecnologias midiáticas saturam a atenção e impedem modos de vida menos reativos e perturbados,

\section{Dossiê o Pensamento Ecológico - https://revistaecopos.eco.ufrj.br/}

ISSN 2175-8689 - v. 23, n. 2, 2020

DOI: 10.29146/eco-pos.v23i2.27459 
considerando o enorme volume de mensagens que são despejadas sobre cada portador de um aparelho de celular hoje (Maitland, 2008; Foy, 2010; Corbin, 2018; Prochnik, 2018).

Considerando as duas perspectivas de silêncio acima mencionadas, pode-se dizer que há a aposta hoje de que o mundo estaria mais barulhento quando comparado com outros tempos e que a busca pelo silêncio, assim como por práticas silenciadoras como o sonlêncio, refletiriam essa particular condição. Diante disso, quais seriam as práticas mais recorrentes para lidar com o suposto ruidoso mundo de hoje? Parte dessas práticas já foram enunciadas no presente estudo e são retomadas aqui, ao lado de outras ainda não abordadas.

O sonlêncio, tal como já enunciado, seria um conjunto vasto de experiências silenciadoras que tomam material sônico específico como meio para amenizar ou eliminar por completo a escuta de outros sons ou ruídos indesejados. A prática consiste em escutar um conteúdo sonoro específico de modo que os ruídos indesejados fiquem imperceptíveis. Como o conteúdo sonoro escutado se estabiliza como um padrão depois de alguns minutos, a sensação relatada por muitos usuários dessa prática é a de um conforto aural, como se o ambiente houvesse silenciado. Isso ocorre porque o ouvido humano funciona reconhecendo picos e variações de sons e ruídos, frente a um fundo que tanto faz se é de fato silencioso ou se está em jogo um padrão sonoro estável (Prochnik, 2018).

Os retiros de silêncio se apresentam como outro conjunto de práticas bastante procuradas para o enfrentamento do suposto aumento da cacofonia do mundo. Basicamente, consistem em encontros nos quais o silêncio é cultivado na maior parte ou na totalidade do tempo que se passa no retiro. Tais práticas podem ou não estar associadas a técnicas de meditação variadas, ligadas a propostas religiosas ou não. Buscam dar a oportunidade para o praticante se desligar do fluxo de diálogos e conversações mediadas pelas tecnologias (como a participação em sites de redes sociais), propondo um mergulho no que se entende como interioridade - a vida mental de cada participante. Muito em voga atualmente, relacionam-se diretamente com a ideia de silêncio interior e buscam silenciar não apenas a fala, mas a mente. Uma rápida busca no Google usando o verbete "retiros

\section{Dossiê 0 Pensamento Ecológico - https://revistaecopos.eco.ufrj.br/}


de silêncio no Brasil" encontra $16.100 .000^{11}$ resultados, evidenciando a popularidade do tema.

Propostas como modos de suspender o fluxo de pensamentos, considerados como ruídos interiores, as diferentes formas de meditação constituem um terceiro conjunto de práticas a ser notado. Existem inúmeras técnicas meditativas disponíveis, sendo que quase todas buscam um foco de atenção em um som, imagem ou ideia, através do qual todos os pensamentos possam ser suspensos temporariamente. Nesse sentido, a prática da meditação reproduziria como método um silêncio relativo - aquele em que o foco da atenção em alguma coisa silencia o mundo - buscando, por fim, o silêncio interior. Praticantes experientes relatam poder entrar no estado de não pensamento sem, necessariamente, recorrerem a técnicas de escuta de sons ou de visualizações de imagens, conseguindo a manutenção do silêncio interior com mais facilidade. A meditação cresceu em popularidade nos últimos anos, particularmente a partir de estudos científicos que comprovaram uma série de benefícios relacionados à sua prática contínua (Goleman e Davidson, 2017).

Dispositivos canceladores de ruídos (noise-cancelling devices) são basicamente tecnologias que detectam ondas de sons e ruídos ambientes e produzem ondas reversas, com frequências capazes de minimizarem ou neutralizarem o barulho ambiente. A recorrência a tais dispositivos constitui um quarto conjunto de práticas silenciadoras a ser destacado. Aqui há dois modelos de tecnologias: os fones canceladores de ruídos (noise-cancelling headphones) e os aparelhos canceladores de ruídos (noise-cancelling gadgets). Alguns exemplares disponíveis no mercado são os fones Dubs e Hush e os aparelhos Sono e Muzo ${ }^{12}$. Hoje já existem empresas especializadas no desenvolvimento desse tipo de tecnologia, prometendo projetos personalizados para residências, escritórios,

\footnotetext{
11 Acesso em16/01/2019.

12 Para mais informações acessar: Sono: https://www.extremetech.com/extreme/170649-sono-a-noisecancelation-and-isolation-device-that-sticks-on-your-window https://www.youtube.com/watch?v=a mHAvWk9iY

Muzo:
}

Dossiê 0 Pensamento Ecológico - https://revistaecopos.eco.ufrj.br/

ISSN 2175-8689 - v. 23, n. 2, 2020

DOI: $10.29146 /$ eco-pos.v23i2.27459 
indústrias, espaços públicos como cabines de trens etc. É o caso, por exemplo, da empresa Silentium ${ }^{13}$

Por fim, como parte das estratégias para diminuir o barulho no dia a dia, intensificam-se os mercados de objetos e aparelhos menos barulhentos, assim como de materiais antirruído. Uma série de empresas oferecem produtos eletrodomésticos e automotivos menos ruidosos, tais como carros, máquinas de lavar roupa, aspiradores de pó, liquidificadores, ventiladores, aparelhos de ar condicionado etc. Uma busca rápida no Google permite encontrar listas e críticas de objetos ofertados pelo mercado como mais silenciosos, indicando como tal característica tem se mostrado atrativa para o público em geral.

Interessante notar como a temática do silêncio/barulho ganha relevância na contemporaneidade, quando empresas buscam desenvolver produtos menos ruidosos como valor agregado para suas marcas, tal como fazem com rótulos como "natural”, "sem aditivos", "reciclável”, "biodegradável”, “socialmente responsável" etc.

Dentro do mercado de tecnologias antirruído, há um sem-número de materiais que são desenvolvidos com a função de promover isolamento acústico para residências, escritórios, indústrias. Tais materiais vão de vidros para janelas a paredes acústicas, revestimentos internos e externos, placas absorventes de sons, dentre outros, sempre com o propósito de promover o controle sobre decibéis indesejados e nocivos.

Ao esboçar um mapeamento das práticas silenciadoras e de tecnologias favoráveis ao silêncio, quer-se enfatizar algo mais profundo em processo, algo nada trivial, que é o fato de o silêncio ganhar a expressão de um produto comercializável, tornando-se um dos novos produtos vendáveis da cultura aural.

O silêncio ganha a expressão de produto comercial em propostas explícitas, como a de "retiros de silêncio", em que o produto em si é tanto o silêncio exterior visto que os encontros são realizados, normalmente, em espaços bucólicos e há a orientação expressa para que se guarde o silêncio em longos períodos durante o

13 https://www.silentium.com/

Dossiê 0 Pensamento Ecológico - https://revistaecopos.eco.ufrj.br/

ISSN 2175-8689 - v. 23, n. 2, 2020

DOI: 10.29146/eco-pos.v23i2.27459 
retiro - quanto o silêncio interior -, uma vez que o objetivo de tais retiros é silenciar a mente e promover a quietude interior.

O silêncio torna-se produto comercial também no trato de tecnologias como o Sono ou o Muzo, que comercializam como proposta central a implementação de bolhas de silêncio em volta dos seus usuários. A proposta dessas novas tecnologias é levar o silêncio para onde quer que se vá, conforme expressa o logo da empresa Silentium, que oferece "o silêncio em um chip".

Indiretamente, é o silêncio também que inspira todo o conjunto de objetos $e$ aparelhos menos barulhentos, tal como já salientado. A ideia de ambientes mais saudáveis, uma vez que se tornem mais silenciosos, promove a cultura do silêncio e sua condição como produto a ser consumido.

Se até há bem pouco o atributo "silencioso", ao lado de outros rótulos circunstanciais, ajudava as empresas a venderem eletrodomésticos e carros como um valor agregado, hoje é o próprio silêncio que se apresenta como produto comercializável.

Mas se o silêncio pode ganhar a feição de um produto a ser avidamente consumido na cultura contemporânea, isso se dá a partir de um aprendizado que treina e habilita a escuta para identificar e perceber as diferentes formas de silêncio. Como se daria este aprendizado? Este é o tema da próxima subseção.

\section{0 aprendizado da escuta do silêncio}

A ideia de um aprendizado da escuta do silêncio poderia soar estranha, visto que, sendo o silêncio uma ausência de sons ou ruídos, não haveria o que escutar, ou aprender a escutar. No entanto, é exatamente esse aspecto paradoxal que torna tal aprendizado relevante para uma melhor compreensão do seu valor da cultura aural contemporânea.

Tomando-se o já clássico trabalho de Jonathan Sterne, The Audible Past (2003), como referência, compreende-se que a história dos sons não pode ficar restrita a suas descrições fenomenológicas, de viés "naturalizante", como processos aurais universais, mas deve levar em conta o conjunto de "tensões,

\section{Dossiê o Pensamento Ecológico - https://revistaecopos.eco.ufrj.br/}


tendências e correntes da cultura da qual emergiram" (Sterne, 2003, p.8). ${ }^{14} 0$ mesmo vale para o silêncio que, obviamente, diz respeito também a uma escuta aprendida. Cabe indagar: como se daria tal aprendizado?

Em primeiro lugar, é necessária a produção de um imaginário que valorize o silêncio como um bem, tomando-o como algo positivo, ao contrário das perspectivas negativas que o desvalorizam e o tomam como um fardo, geralmente imposto. Umas das principais estratégias para essa valorização é vincular a experiência de silêncio à conquista e/ou manutenção de um bem-estar que se traduz diretamente como conquista e manutenção da saúde física e mental e da paz interior. ${ }^{15} \mathrm{~A}$ propósito, o conjunto de obras de autoajuda que glorificam o silêncio atualmente colaboram bastante nesse sentido.

Recorrer ao discurso científico faz parte da estratégia mencionada. Narrativas sobre os malefícios dos ambientes barulhentos e os benefícios do silêncio sempre recorrem a um discurso supostamente "cientificamente comprovado", como atestado definitivo para a veracidade das suas afirmações. 0 que tais narrativas promovem, em primeiro lugar, é a (re)valorização do silêncio em uma história na qual este tantas vezes foi tomado como algo negativo, conforme já vimos. 0 silêncio, assim, ganha status no âmbito das "boas práticas", capazes de promover a saúde, ao lado de alimentação saudável, exercícios físicos regulares, restrição ao consumo de álcool, dentre outras.

Uma vez conquistado o valor do silêncio com o auxílio de discursos científicos (e/ou pseudocientíficos) e da literatura de autoajuda, são necessárias práticas que induzam uma escuta diferenciada e que esta seja aprimorada continuamente para que o silêncio - seja exterior ou interior - possa ser identificado e cultivado. Tais práticas incluem todas aquelas acima apresentadas. Ou seja, não há aprendizado da escuta do silêncio sem uma cultura que promova tal aprendizado, do qual participam diversas modalidades de consumo do silêncio, tal como visto.

\footnotetext{
14 Parte dessa argumentação é explorada em estudo anterior, tal como pode ser conferido em Pereira, 2018. pp. 19 e 20.

15 Um estudo da ideia de bem-estar, assim como correlações deste e produtos da cultura aural contemporânea, foi tema anterior de pesquisa. (Ver em Pereira, 2018)
}

\section{Dossiê 0 Pensamento Ecológico - https://revistaecopos.eco.ufrj.br/}


Da produção de valor às práticas silenciadoras, do mercado aos autores que discutem diferentes tipos de silêncio que precisam ser desvendados e recuperados, todos esses pontos refletem a cultura de onde emerge o aprendizado da escuta do silêncio que, por fim, acaba por lhe dar um valor positivo e o status de produto comercial a ser consumido.

\section{Considerações finais}

O presente artigo insere-se em uma pesquisa mais ampla que investiga a cultura aural em suas relações com as dinâmicas midiáticas contemporâneas, articulando, assim, o campo dos Estudos de Som com a Comunicação.

O silêncio compareceu como objeto na referida pesquisa como um desdobramento de escutas outras, daquilo que foi nomeado como produtos do M.E.R.S.B.E. - Mercado de Ruídos e Sons para o Bem-Estar (Pereira, 2018). Considerando os autores, bem como o conjunto de práticas e produtos que cotejam o silêncio, parece haver um consenso quanto às relações diretas entre bem-estar e silêncio. Tais relações ganham sustentação na literatura de autoajuda, que agora parece ter encontrado no silêncio um novo filão, e em estudos científicos ou pseudocientíficos, a maioria deles de natureza médica, apresentando uma narrativa invertida, na qual o aumento da poluição sonora estaria associado a uma série de malefícios e doenças. Portanto, silenciar o mundo e as pessoas poderia ser visto como a conquista de um bem comum.

A ideia de "bem-estar" deve ser pensada criticamente, como um valor que parece representar uma ideologia, na medida em que articula um conjunto de variáveis como saúde, prosperidade, paz de espírito e criatividade, dentre outros, a um conjunto de práticas, comportamentos e consumo que movimenta um vasto e complexo mercado (Pereira, 2018).

Interessante observar que, no movimento de silenciamento do mundo, não apenas se deve estar atento ao monitoramento do barulho do outro - através de medições com aparelhos específicos, denúncias e enquadramentos em leis específicas que lidam com o barulho no espaço urbano -, mas também, e talvez

\section{Dossiê o Pensamento Ecológico - https://revistaecopos.eco.ufrj.br/}


mais importante, atento ao silêncio pessoal. Não apenas em relação ao barulho que se possa produzir no dia a dia, mas em uma dimensão mais profunda, no interior de si.

O movimento coletivo que agora busca tornar o mundo mais silencioso seja mundo exterior, seja mundo interior - é revelador de um paradoxo que demanda uma exploração atenciosa, que considere algumas de suas nuances.

Em primeiro lugar, é preciso considerar a proposta do sonlêncio como uma modulação do silêncio na contemporaneidade. Tal proposta, como apresentada, ao implicar ruídos como material de escuta para a conquista de um ambiente mais silencioso, estaria colaborando para tornar o mundo efetivamente mais silencioso ou, ao contrário, favoreceria o aumento da cacofonia e do barulho no mundo, uma vez que, na prática, difunde o consumo de mais ruídos para a conquista dos seus objetivos?

Em um outro movimento, é preciso considerar a experiência do silêncio exterior como uma experiência na qual, inevitavelmente, sons e ruídos interiores diversos emergem depois de algum tempo, sejam eles vozes, chamados, zumbidos, como no caso das pessoas com tinido, sons do sistema nervoso e circulatório, dentre outras experiências (Picard, 1953; Cage, 1961; Maitland, 2010; Foy, 20818; Prochnik, 2019). Tal perspectiva não apenas daria sustentação à afirmação de Cage de que o silêncio absoluto é impossível, como também denuncia que aqueles que acreditam encontrá-lo inevitavelmente escutariam outros sons e ruídos, o que mantém a perspectiva de que a busca do silêncio favorece a profusão de ruídos no mundo, problemática de algum modo análoga àquela apresentada anteriormente, com a prática do sonlêncio.

Considerando os pontos acima, ou seja, a ideia de que o silêncio buscado acaba por se revelar mais como um ideal do que como uma experiência passível de realização, valeria indagar: seria a busca pelo silêncio pregada por tantos autores e confirmada em tantas formas de consumo temático uma ideologia disfarçada de experiência aural? Isso talvez explique o porquê de, cada vez mais, autores que valorizam e advogam pela busca dos silêncios exterior ou interior se inscrevam no 
campo da autoajuda, com filiações religiosas mais ou menos explícitas, encabeçando listas de best-sellers.

Encerrando essas considerações, propõe-se afirmar o silêncio como um objeto legítimo da cultura aural contemporânea. Objeto idealizado e ideologizado de diversas maneiras, assim como são múltiplas as formas em que se materializa. Ainda que isso se mostre impossível e o mundo siga barulhento, caberá ao campo dos Estudos de Som e áreas afins apontar os papeis e forças que o silêncio representa na cultura aural contemporânea, os modos como ele emerge como objeto de desejo, se revaloriza, como é modulado, como se constrói a sua escuta e mesmo como se vende, seja como experiência sonora, seja como ideologia ou poesia mística. Tais foram os movimentos que inspiraram e nortearam o presente artigo.

\section{Referências Bibliográficas}

BOIVIN, Nicole. Material cultures, material minds: the impact of things on human thought, society and evolution. Cambridge: Cambridge Univ. Press, 2009.

BROX, Jane. Silence: A Social History of One of the Least Understood Elements of Our Lives. Houghton M. Harcourt, nyc, 2019.

BULL, Michael. \& BACK, Les., (orgs.), The auditory Culture Reader. Berg. Pub., Oxford and New York, 2003.

CAGE, John. Silence - Lectures and writings by John Cage. Wesleyan Univ. Press. New England, 1961.

CASTILLO, Mauricio. Sounds of Silence. American Journal of Neuroradiology August 2011, 32 (7) 1155-1157; DOI: https://doi.org/10.3174/ajnr.A2283

CORBIN, Alain. A History of Silence - From the Renaissance to Present Day. Polity Press, Cambridge, UK, 2018 (Edição para Kindle).

DE NORA, Tia. Music in everyday life. Cambridge Univ. Press. Massachussets/London, 1992.

FOY, George Michelsen. Zero Decibels: The Quest For Absolute Silence. Scribner, NYC, 2010 (Edição para Kindle)

GOLEMAN, David e DAVIDSON, Richard. A Ciência da Mediatação. Objetiva, Rio de Janeiro, 2017 (Edição para Kindle)

HANH, Thich Nhat. Silêncio: o poder da quietude em um mundo barulhento. HarperCollins Brasil, 2018 (Edição para Kindle).

Dossiê 0 Pensamento Ecológico - $\underline{\text { https://revistaecopos.eco.ufri.br/ }}$

ISSN 2175-8689 - v. 23, n. 2, 2020

DOI: 10.29146/eco-pos.v23i2.27459 
KAGGE, Erling. Silêncio na era do ruído. Objetiva, Rio de Janeiro, 2016 (Edição para Kindle)

KRAUS, Nina. e NICOL, Trent. The power of sound for brain health. Nature Human Behaviour. (2017) doi:10.1038/s41562-017-0201-7

MAITLAND, Sara. O Livro do Silêncio. Estrela Polar. Alfragide, Portugal, 2008 (Edição para Kindle)

OCHOA GAUTIER, Ana Maria, Silence. In: NOVAK, D. e SAKAKEENY, M. (orgs), Keywords in Sound. Duke Univ. Press, 2015. (versão para Kindle)

PEREIRA, Vinícius Andrade. MERSBE - Mercado de Ruídos e Sons para o Bem-Estar: Modulações da Escuta e Cultura Aural Contemporânea. Artigo apresentado no GT Estudos de Som e Música na XXVII COMPÓS. PUC-MG, Belo Horizonte, 05 a 08 de junho de 2018.

PICARD, Max. The World of Silence. Gateway, Austin, 1953.

PROCHNIK George. Pursuit of Silence: Listening for Meaning in a World of Noise. New York: Doubleday; 2010

SÁ, Simone Pereira de. A trilha sonora de uma história silenciosa: som, música, audibilidades e tecnologias na perspectiva dos Estudos de Som. In: SÁ, Simone Pereira de, (org.) Rumos da Cultura da Música - Negócios, Estéticas, Linguagens e Audibilidades. Porto Alegre: Sulina, 2010.

SCHAFER, Raymond Murray. A Afinação do Mundo. São Paulo: UNESP, 2001.

STERNE, Jonathan. The Audible Past: Cultural Origins of Sound Reproduction. Duke University Press, Durham and London, 2003.

THOMPSON, Emily. The Soundscape of Modernity: Architectural Acoustics and the Culture of Listening in America 1900-1930. Cambridge: MIT Press, 2002 (pp. 1-12).

VOEGELIN, Salomé. Listening to Noise and Silence - Towards a Philosophy of Sound Art. Continuum. NYC/LONDON, 2010. 